\title{
Implementasi Algoritma Welch-Powell pada Pengaturan Lampu Lalu Lintas Pasteur Bandung
}

\author{
Muammar Yusuf Fakhri*, Erwin Harahap \\ Prodi Matematika, Fakultas Matematika dan Ilmu Pengetahuan Alam, \\ Universitas Islam Bandung, Indonesia. \\ *ummarfakhrie@gmail.com,erwin2h@gmail.com
}

\begin{abstract}
Traffic queues are a common problem serving various cities in Indonesia. One way to minimize traffic queues is to use traffic lights with appropriate cycle time settings. The existence of traffic lights is very helpful to curb traffic, but there is still a less than optimal use of traffic lights. For example, in the traffic lane in the Pasteur area of Bandung, determining which flow should be green or red first and how long it takes the lights to turn on in each color. One solution to solve this problem is through the point coloring approach of the Graph by implementing the Welch-Powell algorithm and support with Queuing Theory as a representation of the traffic light model. Using the information about the direction of the currents in the Pasteur junction, a graph can be formed and the point coloring is performed using the Welch-Powell algorithm. The results of the implementation of the WelchPowell algorithm obtained the duration of one new cycle at traffic lights. Furthermore, the results obtained by testing with Queuing Theory where the results obtained that the duration of the new pasteur traffic light is more optimal than one traffic light cycle based on field data.
\end{abstract}

Keywords: Graph Coloring, Welch-Powell, Queue, Traffic Light.

Abstrak. Antrian lalu lintas menjadi permasalahan umum yang dihadapi berbagai kota di Indonesia. Salah satu cara meminimalisir antiran lalu lintas adalah melalui penggunaan lampu lalu lintas dengan pengaturan siklus waktu yang tepat. Keberadaan lampu lalu lintas sangat membantu untuk menertibkan lalu lintas, namun masih ada kasus penggunaan lampu lalu lintas yang kurang optimal. Sebagai contoh pada persimpangan lalu lintas di kawasan Pasteur Bandung, penentuan arus mana yang harus hijau atau merah terlebih dahulu dan berapa lama waktu lampu untuk menyala dalam masing-masing warna. Salah satu solusi untuk mengatasi masalah tersebut adalah melalui pendekatan pewarnaan titik pada Graf dengan mengimplementasikan algoritma Welch-Powell serta dikaitkan dengan Teori Antrian sebagai representasi model lampu lalu lintas. Melalui informasi tentang arah dari arus-arus yang berada dalam Persimpangan Pasteur, dapat dibentuk sebuah graf dan dilakukan pewarnaan titik dengan algoritma Welch-Powell. Hasil dari implementasi algoritma Welch-Powell didapatkan durasi satu siklus baru pada lampu lalu lintas. Selanjutnya dimana diperoleh hasil dilakukan pengujian dengan Teori Antrian dimana diperoleh hasil bahwa durasi lampu lalu lintas pasteur yang baru lebih optimal dibandingkan dengan satu siklus lampu lalu lintas berdasarkan data lapangan.

Kata Kunci: Pewarnaan Graf, Welch-Powell, Antrian, Lampu Lalu Lintas. 


\section{A. Pendahuluan}

Permasalahan lalu lintas tidak akan pernah lepas dari antrian kendaraan, permasalahan umum yang terjadi utamanya pada kota-kota besar. Beberapa faktor penyebabnya adalah kurang disiplinnya pengendara pada persimpangan jalan, dan volume kendaraan yang semakin bertambah. Permasalahan ini dapat diselesaikan salah satunya dengan pengaturan lampu lalu lintas (traffic light).

Menurut Soimah [1] Pengaturan lampu lalu lintas (traffic light) pada saat ini masih kurang optimal karena pada persimpangan jalan banyak ditemui lampu lalu lintas (traffic light) dengan durasi lampu hijau yang singkat dan lampu merah yang lama, salah satunya di persimpangan pasteur. Hal ini menyebabkan terjadinya peningkatan antrian kendaraan pada persimpangan tersebut dan menimbulkan kemacetan.

Oleh karena itu, pengaturan sinyal yang optimal dari lampu lau lintas sangat diperlukan untuk mengatur arus lalu lintas agar tidak terjadi permasalahan. Pengoptimalan lampu lalu lintas dapat dianalogikan dalam prespektif graf, yaitu dengan memodelkan persimpangan dalam bentuk graf. Simpul pada graf menunjukkan arah perjalanan dari jalan X menuju Y, sedangkan sisinya menunjukkan arah perjalanan yang tidak boleh dilakukan secara bersamaan. Kemudian dengan metode pewarnaan simpul menggunakan algoritma Welch-Powell [1] akan menghasilkan arus-arus yang dapat berjalan secara bersamaan, selain itu juga diperoleh alternatif durasi siklus baru yang lebih optomal. Durasi lampu lalu lintas hasil Algoritma WelchPowel dapat diuji keoptimalannya dengan Teori Antrian dan membandingkannya dengan data lapangan.

Berdasarkan latar belakang yang telah diuraikan diatas maka masalah yang akan dibahas adalah bagaimana mengoptimalkan pengaturan lampu lalu lintas pasteur, Bandung pada jam 05.00-08.00 WIB. Selanjutnya, tujuan dalam penelitian ini diuraikan dalam pokok-pokok sbb.

1. Implementasi Pewarnaan Graf dengan Algoritma Welch-Powell untuk optimasi Lampu Lalu Lintas.

2. Menguji keoptimalan Lampu Lalu Lintas menggunakan Model Antrian

\section{B. Metodologi Penelitian}

\section{Teori Antrian}

Menurut Siagian [4], antrian adalah suatu garis tunggu dari nasabah (satuan) yang memerlukan layanan dari satu atau lebih pelayanan (fasilitas layanan). Kejadian garis tunggu timbul disebabkan oleh kebutuhan layanan yang melebihi kemampuan (kapasitas) pelayanan atau fasilitas layanan, sehingga nasabah tidak bisa segera mendapat layanan.

Berikut adalah rumus- rumus Model Antrian dalam lalu lintas berserta keterangan notasinya :

$$
\mathrm{L}_{\mathrm{s}}=\frac{\lambda}{\mu-\lambda} \quad \mathrm{L}_{\mathrm{q}}=\frac{\lambda^{2}}{\mu(\mu-\lambda)} \quad \mathrm{W}_{\mathrm{s}}=\frac{1}{\mu-\lambda} \quad \mathrm{W}_{\mathrm{q}}=\frac{\rho}{\mu(1-\rho)} \quad \rho=\frac{\lambda}{\mu}
$$

Dimana,

$\lambda$ : jumlah rata-rata kendaraan yang datang per satuan waktu.

$\mu$ : jumlah rata-rata kendaraan yang dilayani per satuan waktu.

$\rho$ : tingkat insensitas/kegunaan/utilitas fasilitas pelayanan.

Ls : jumlah rata-rata kendaraan yang diharapkan menunggu dalam sistem.

Lq : jumlah rata-rata kendaraan yang diharapkan menunggu dalam antrian.

Ws: waktu yang diharapkan kendaraan seleama dalam sistem.

Graf

Wq: waktu yang diharapkan kendaraan seleama dalam antrian.

Menurut John [2] sebuah graf $\mathrm{G}$ terdiri dari suatu himpunan $\mathrm{V}$ yang merupakan vertex-vertex (simpul-simpul) dan suatu himpunan $E$ dari sisi-sisi sedemikian rupa sehingga setiap sisi $e \in E$ dikaitkan dengan pasangan simpul tak terurut. Jika terdapat sebuah rusuk $e$ yang menghubungkan simpul $v$ dan $w$, dapat dinyatakan dengan $e=(v, w)$ atau $e=(w, v)$. Dalam konteks ini, $(v, w)$ menyatakan sebuah sisi antara simpul $v$ dan simpul $w$ dalam sebuah graf dan 
buka sebuah pasangan terurut. Misal $G$ adalah graf dengan himpunan simpul $V(G)=\{a, b, c, d, e\}$ dan $E(G)=\{(a, b),(b, c),(c, d),(d, e),(e, a),(e, b),(e, c),(d, b)\}$.

\section{Pewarnaan Graf}

Pewarnaan graf (graph coloring) adalah sebuah metode pelabelan pada sebuah graf. Pelabelan tersebut merupakan pemberian warna pada simpul, sisi ataupun wilayah (region). Dalam pewarnaan ada indeks kromatik atau angka kromatik sisi yang disimbolkan $\chi^{\prime}(\mathrm{G})$ yaitu Angka terkecil yang diperlukan untuk pewarnaan sisi graf G.

\section{Algoritma Welch-Powell}

Menurut Munir [3]Algoritma Welch-Powell dinyatakan sebagai berikut:

1. Urutkan titik-titik dalam graf $\mathrm{G}$ dalam derajat dimulai dari derajat terbesar ke derajat terkecil.

2. Gunakan warna pertama untuk mewarnai titik pertama (yang mempunyai derajat paling tinggi) dan titik lain (sesuai dengan urutannya) selama titik-titik tersebut tidak saling bertetangga. Jika salah satu dari titik-titik tesebut bertetangga maka masuk kelangkah selanjutnya.

3. Mulailah lagi dengan titik yang memiliki derajat tertinggi berikutnya dalam daftar terurut yang masih belum diwarnai. Ulangi proses ini dengan menggunakan warna kedua.

Ulangi pemberian warna-warna sampai semua titik telah diwarnai.

\section{Hasil Penelitian dan Pembahasan}

\section{Data Penelitian}

Berikut adalah Data durasi Lampu Lalu Lintas Pasteur Bandung dalam satu siklus:

Tabel 1. Durasi siklus Lampu Lalu Lintas Pasteur Bandung 05.00-08.00 WIB.

\begin{tabular}{|l|c|c|c|c|c|}
\hline & $\begin{array}{c}\text { Jl. Gunung } \\
\text { Batu menuju Jl. } \\
\text { Dr. Junjungan } \\
\text { (Detik) }\end{array}$ & $\begin{array}{c}\text { Tol Pasteur } \\
\text { menuju Dr. } \\
\text { Junjungan } \\
\text { (Detik) }\end{array}$ & $\begin{array}{c}\text { Jl. Surya } \\
\text { Sumantri } \\
\text { menuju Jl. Tol } \\
\text { Pasteur (Detik) }\end{array}$ & $\begin{array}{c}\text { Jl. Dr. } \\
\text { Junjungan } \\
\text { menuju Jl. } \\
\text { Surya } \\
\text { Sumantri } \\
\text { (Detik) }\end{array}$ & $\begin{array}{c}\text { Jl. Dr. } \\
\text { Junjungan } \\
\text { menuju Tol } \\
\text { Pasteur (Detik) }\end{array}$ \\
\hline Merah & 170 & 150 & 170 & 150 & 135 \\
\hline Hijau & 65 & 85 & 65 & 85 & 100 \\
\hline Total & 235 & 235 & 235 & 235 & 235 \\
\hline
\end{tabular}

Sumber: Dinas Perhubungan (DISHUB) Kota Bandung

Berikut adalah Data kedatangan kendaraan pada Lampu Lalu Lintas Pasteur Bandung :

Tabel 2. Jumlah Kedatangan kendaraan pada Lampu Lalu Lintas Pasteur Bandung 05.00-08.00 WIB.

\begin{tabular}{|c|c|c|c|c|}
\hline \multirow{2}{*}{ Tanggal } & \multicolumn{4}{|c|}{ Jumlah kedatangan dari ruas jalan (kendaraan) } \\
\cline { 2 - 5 } & Jl. Junjungan & Jl. Gunung Batu & Jl. Surya Sumantri & Tol Pasteur \\
\hline 03-Nov & 4521 & 1130 & 1861 & 2898 \\
\hline 04-Nov & 4769 & 1192 & 1815 & 2983 \\
\hline 05-Nov & 4305 & 1076 & 1428 & 2549 \\
\hline 06-Nov & 3995 & 999 & 1555 & 2723 \\
\hline 07-Nov & 4694 & 1177 & 1833 & 2997 \\
\hline
\end{tabular}




\begin{tabular}{|c|c|c|c|c|} 
08-Nov & 5188 & 1297 & 1883 & 3244 \\
\hline 09-Nov & 3472 & 868 & 1276 & 2257 \\
\hline Jumlah & 30943 & 7739 & 11651 & 19649 \\
\hline
\end{tabular}

Sumber: Dinas Perhubungan (DISHUB) Kota Bandung

Data Pelayanan didapat dengan pengamatan melalui CCTV Area Traffic Control System (ATCS) kota Bandung pada Simpang Pasteur, Bandung. Pengamatan dilakukan sebanyak 15 kali. Pengamatan yang dilakukan berupa menghitung jumlah kendaraan yang keluar dari lampu lalu lintas dalam satu siklus lampu hijau. Waktu pelayanan per kendaraan dilambangkan dengan $\frac{1}{\mu}$. Rata -rata waktu pelayanan sebagai berikut:

1. Waktu Pelayanan dari ruas Jl. Junjungan $: \frac{1}{\mu}=0,318$ detik/kendaraan

2. Waktu Pelayanan dari ruas Jl. Gunung Batu $: \frac{1}{\mu}=2,422$ detik/kendaraan

3. Waktu Pelayanan dari ruas Jl. Surya Sumantri $: \frac{1}{\mu}=0,540$ detik/kendaraan

4. Waktu Pelayanan dari ruas Jl. Tol Pasteur : $\frac{1}{\mu}=0,325$ detik/kendaraan

\section{Implementasi Algoritma Welch-Powell}

Akan di Ilustrasikan Arus -Arus Lalu Lintas yang berada di Simpang Pasteur sebagai berikut :

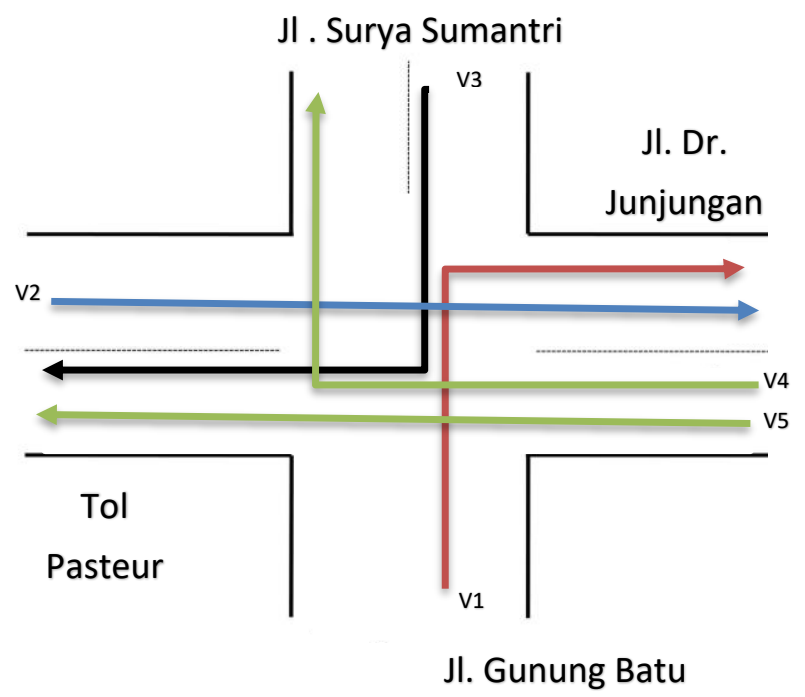

Gambar 1. Ilustrasi Arus Denah Pasteur

Keterangan:

v1 = arus dari Jl. Gunung Batu menuju Jl. Dr. Junjungan.

v2 $=$ arus dari Tol Pasteur menuju Dr. Junjungan.

v3 = arus dari Jl. Surya Sumantri menuju Tol Pasteur.

v4 = arus dari Jl. Dr. Junjungan menuju J1. Surya Sumantri.

v5 = arus dari Jl. Dr. Junjungan menuju Tol Pasteur.

Arus-arus yang uncompatible (tidak boleh berjalan bersamaan) adalah

Arus v1 tidak boleh berjalan bersamaan dengan v2, v4, dan v5.

Arus v2 tidak boleh berjalan bersamaan dengan v1, v3, dan v4.

Arus v3 tidak boleh berjalan bersamaan dengan v2, v4, dan v5.

Arus v4 tidak boleh berjalan bersamaan dengan v1, v3, dan v2.

Arus v5 tidak boleh berjalan bersamaan dengan v1, dan v3. 
Kemudian dibuat sebuah Graf yaitu Graf Pasteur dengan arus-arus yang berada dalam simpang pasteur sebagai dengan vertek dan arus-arus yang tidak boleh berjalan bersamaan verteknya saling bersisian. Graf akan terbentuk sebagai berikut.

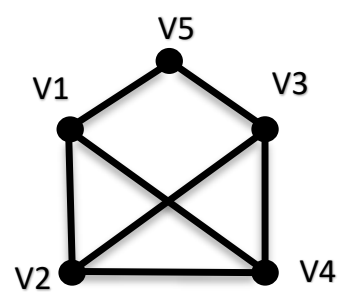

Gambar 2. Graf Pasteur

Selanjutnya dari Graf Pasteur akan diberi warna pada verteks menggunakan Algoritma Welch-Powell. Langkah pertama dalam Algoritma Welch-Powell yaitu menentukan jumlah derajat dari masing- masing verteks. Jumlah derajat dari verteks - verteks Graf Pasteur beserta pemberian warna verteks menggunakan Algoritma Welch-Powell disajikan dalam Table 3.

Tabel 3. Durasi siklus Lampu Lalu Lintas Pasteur Bandung 05.00-08.00 WIB

\begin{tabular}{|c|c|c|c|c|c|}
\hline Vertek & $v_{1}$ & $v_{2}$ & $v_{3}$ & $v_{4}$ & $v_{5}$ \\
\hline Derajat & 3 & 3 & 3 & 3 & 2 \\
\hline Warna & Merah & Biru & Merah & Kuning & Biru/kuning \\
\hline
\end{tabular}

Graf setelah pewarnaan verteks menggunakan Algoritma Welch-Powell sebagai berikut:

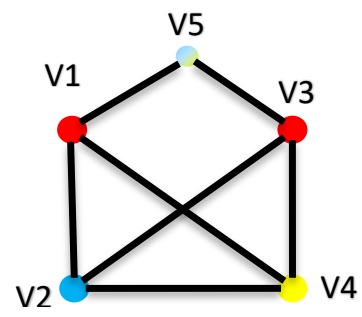

Gambar 3. Graf Warna Pasteur

Dari Pewarnaan graf di atas diperoleh 3 warna yang berbeda, artinya bilangan kromati $(\chi)=3$ dan arus arus yang dapat berjalan bersamaan sebagai berikut :

1. arus v1 berjalan bersama dengan arus v3

2. arus v2 berjalan bersama dengan arus v5

3. arus v4 berjalan bersama dengan arus v5

Selanjutnya menentukan alternatif penyelesaian durasi lampu hijau dan lampu merah menyala. Berdasarkan data simpang pasteur pada jam 05.00-08.00 memiliki durasi siklus normal 235 detik, setelah dilakukan pembagian dengan bilangan $\operatorname{kromati}(\chi)=3$ diperoleh durasi lampu hijau menyala masing masing 78 detik. Durasi lampu lalu lintas setelah implementasi Algoritma Welch-powel disajikan dalam Tabel 4. 
Tabel 4. Durasi siklus Lampu Lalu hasil Algoritma Welch-Powell

\begin{tabular}{|c|c|c|c|c|c|}
\hline & $\begin{array}{c}\text { Jl. Gunung } \\
\text { Batu menuju Jl. } \\
\text { Dr. Junjungan } \\
\text { (Detik) }\end{array}$ & $\begin{array}{c}\text { Tol Pasteur } \\
\text { menuju Dr. } \\
\text { Junjungan } \\
\text { (Detik) }\end{array}$ & $\begin{array}{c}\text { Jl. Surya } \\
\text { Sumantri } \\
\text { menuju Jl. Tol } \\
\text { Pasteur (Detik) }\end{array}$ & $\begin{array}{c}\text { Jl. Dr. } \\
\text { Junjungan } \\
\text { menuju Jl. } \\
\text { Surya } \\
\text { Sumantri } \\
\text { (Detik) }\end{array}$ & $\begin{array}{c}\text { Jl. Dr. } \\
\text { Junjungan } \\
\text { menuju Tol } \\
\text { Pasteur (Detik) }\end{array}$ \\
\hline Merah & 157 & 157 & 157 & 157 & 79 \\
\hline Hijau & 78 & 78 & 78 & 78 & 156 \\
\hline Total & 235 & 235 & 235 & 235 & 235 \\
\hline
\end{tabular}

\section{Model Teori Antrian}

Untuk Memodelkan Antrian Lampu lalu lintas pasteur langkah pertama adalah mencari rata-rata kedatangan kendaraan $(\lambda)$

Rata-rata kedatangan dari ruas Jl. Junjungan :

$$
\begin{gathered}
\lambda=\frac{\sum_{i=1}^{m} x_{i} f_{i}}{n}=\frac{\sum_{i=1}^{15} x_{i} f_{i}}{84}=\frac{30943}{84}=368,37 \text { kendaraan } / \text { siklus } \\
\lambda \approx 368 \text { Kendaraan/siklus }
\end{gathered}
$$

Kemudian mencari banyak kendaraan dilayanani $(\mu)$ dalam satu siklus. Misal $\mu_{\mathrm{a}}$ adalah banyak kendaraan dilayani dengan data durasi lampu hijau awal dan $\mu_{\mathrm{b}}$ adalah banyak kendaraan dilayani dengan data durasi lampu hijau hasil Implementasi Algoritma Welch-Powell .

Pelayanan dari ruas J1. Junjungan .

$$
\begin{gathered}
\frac{1}{\mu}=0,318 \mathrm{detik} / \text { kendaraan } \\
\mu=3,14 \text { Kendaraan/detik }
\end{gathered}
$$

Durasi maksimal data awal lampu hijau dari ruas Jl. Junjungan adalah 100 detik sehingga

$$
\mu_{a}=3,144 \times 100=314,4 \approx 314 \text { Kendaraan/Siklus }
$$

Sedangkan durasi maksimal lampu hijau dengan Algoritma Welch-Powell dari ruas Jl. Junjungan adalah 156 detik Sehingga

$$
\mu_{b}=3,14 \times 156=490,56 \approx 490 \text { Kendaraan/Siklus }
$$

Setelah mengetahui nilai $\lambda, \mu_{a}$ dan $\mu_{b}$ dari masing masing ruas jalan, masukan kedalam rumus- rumus Model Antrian. Berikut adalah tabel ringkasan perbandingan hasil perhitungan model antrian Lampu Lalu Lintas Pasteur Bandung.

Tabel 5. Hasil Model Antrian Ruas Jl. Junjungan

\begin{tabular}{|l|c|c|c|c|}
\hline & $\begin{array}{c}\boldsymbol{L}_{\boldsymbol{s}} \\
\text { (kendaraan) }\end{array}$ & $\begin{array}{c}\boldsymbol{L}_{\boldsymbol{q}} \\
\text { (kendaraan) }\end{array}$ & $\begin{array}{c}\boldsymbol{W}_{\boldsymbol{s}} \\
\text { (siklus) }\end{array}$ & $\begin{array}{c}\boldsymbol{W}_{\boldsymbol{q}} \\
\text { (siklus) }\end{array}$ \\
\hline Siklus dengan data awal & -6 & -7 & $-0,019$ & $-0,022$ \\
\hline Siklus dengan Algoritma Welch-Powell & 2 & 2 & 0,008 & 0,006 \\
\hline
\end{tabular}

Hasil perhitungan model antrian dengan data siklus awal bernilai negatif ini artinya antrian tidak normal atau tidak steady state biasanya. steady state terjadi apabila $\lambda<\mu$. Dapat disimpulkan perhitungan model antrian dengan durasi siklus hasil Algoritma Welch-Powell lebih optimal dibandingkan durasi siklus data awal dilihat dari ruas Jl. Jungjungan. 
Tabel 6. Hasil Model Antrian Ruas Jl. Surya Sumantri.

\begin{tabular}{|l|c|c|c|c|}
\hline & $\begin{array}{c}\boldsymbol{L}_{\boldsymbol{s}} \\
\text { (kendaraan) }\end{array}$ & $\begin{array}{c}\boldsymbol{L}_{\boldsymbol{q}} \\
\text { (kendaraan) }\end{array}$ & $\begin{array}{c}\boldsymbol{W}_{\boldsymbol{s}} \\
\text { (siklus) }\end{array}$ & $\begin{array}{c}\boldsymbol{W}_{\boldsymbol{q}} \\
\text { (siklus) }\end{array}$ \\
\hline Siklus dengan data awal & -7 & -8 & $-0,053$ & $-0,061$ \\
\hline Siklus dengan Algoritma Welch-Powell & 27 & 26 & 0,2 & 0,193 \\
\hline
\end{tabular}

Hasil perhitungan model antrian dengan data siklus awal bernilai negatif ini artinya antrian tidak normal atau tidak steady state biasanya. steady state terjadi apabila $\lambda<\mu$. Dapat disimpulkan perhitungan model antrian dengan durasi siklus hasil Algoritma Welch-Powell lebih optimal dibandingkan durasi siklus data awal dilihat dari ruas Jl. Surya Sumantri.

Tabel 7. Hasil Model Antrian Ruas Jl. Tol Pasteur.

\begin{tabular}{|l|c|c|c|c|}
\hline & $\begin{array}{c}\boldsymbol{L}_{\boldsymbol{s}} \\
\text { (kendaraan) }\end{array}$ & $\begin{array}{c}\boldsymbol{L}_{\boldsymbol{q}} \\
\text { (kendaraan) }\end{array}$ & $\begin{array}{c}\boldsymbol{W}_{\boldsymbol{s}} \\
\text { (siklus) }\end{array}$ & $\begin{array}{c}\boldsymbol{W}_{\boldsymbol{q}} \\
\text { (siklus) }\end{array}$ \\
\hline Siklus dengan data awal & 8 & 7 & 0,167 & 0,032 \\
\hline Siklus dengan Algoritma Welch-Powell & 39 & 38 & 0,893 & 0,163 \\
\hline
\end{tabular}

Nilai Ls Perhitungan dengan siklus data awal memiliki hasil lebih kecil dari Siklus yang diberikan Algoritma Welch-Powell. Nilai Lq Perhitungan dengan siklus data awal memiliki hasil lebih kecil dari. Siklus yang diberikan Algoritma Welch-Powell. Nilai Ws Perhitungan dengan siklus data awal memiliki hasil lebih kecil dari Siklus yang diberikan Algoritma WelchPowell. Nilai Wq Perhitungan dengan siklus data awal memiliki hasil lebih kecil dari Siklus yang diberikan Algoritma Welch-Powell. Dapat disimpulkan perhitungan model antrian dengan durasi siklus hasil Algoritma Welch-Powell Tidak lebih optimal dibandingkan durasi siklus data awal dilihat dari ruas Jl. Tol Pasteur.

Tabel 8. Hasil Model Antrian Ruas J1. Gunung Batu

\begin{tabular}{|l|c|c|c|c|}
\hline & $\begin{array}{c}\boldsymbol{L}_{\boldsymbol{s}} \\
\text { (kendaraan) }\end{array}$ & $\begin{array}{c}\boldsymbol{L}_{\boldsymbol{q}} \\
\text { (kendaraan) }\end{array}$ & $\begin{array}{c}\boldsymbol{W}_{\boldsymbol{s}} \\
\text { (siklus) }\end{array}$ & $\begin{array}{c}\boldsymbol{W}_{\boldsymbol{q}} \\
\text { (siklus) }\end{array}$ \\
\hline Siklus dengan data awal & 1 & 1 & 0,015 & 0,009 \\
\hline Siklus dengan Algoritma Welch-Powell & 1 & 1 & 0,010 & 0,005 \\
\hline
\end{tabular}

Nilai Ls Perhitungan dengan siklus data awal memiliki hasil sama dengan Siklus yang diberikan Algoritma Welch-Powell. Nilai Lq Perhitungan dengan siklus data awal memiliki hasil sama dengan Siklus yang diberikan Algoritma Welch-Powell. . Nilai Ws Perhitungan dengan siklus data awal memiliki hasil lebih besar dari Siklus yang diberikan Algoritma Welch-Powell. Nilai Wq Perhitungan dengan siklus data awal memiliki hasil lebih besar dari Siklus yang diberikan Algoritma Welch-Powell. Dapat disimpulkan perhitungan model antrian dengan durasi siklus hasil Algoritma Welch-Powell lebih optimal dibandingkan durasi siklus data awal dilihat dari ruas Jl. Gunung Batu.

Hasil dari Model Antrian untuk mengukur Optimal Lampu Lalu Lintas dengan durasi hasil Algoritma Welch-Powell. Durasi yang diberikan lebih optimal dari ruas Jl. Dr. Junjungan, ruas Jl. Gunung Batu dan ruas Jl. Surya Sumantri. Tetapi tidak optimal dari ruas Jl. Tol Pasteur.

\section{Kesimpulan}

Berdasarkan pembahasan dalam penelitian ini, peneliti menyimpulkan lampu lalu lintas Pasteur bandung periode 05.00-08.00 lebih optimal menggunakan durasi yang didapat dari Algoritma Welch-Powell dibandingkan Durasi lapangan. 
98 | Muammar Yusuf Fakhri, et al.

\section{Daftar Pustaka}

[1] A. M. Soimah, "Pewarnaan Simpul Dengan Algoritma Welch Powell Pada Traffic Light di Yogyakarta," JURNAL FOURIER, vol. II, no. 2, pp. 73-79, 2013.

[2] R. Johnsoundbaugh, Matematika Diskrit, Jakarta: PT Prenhallindo, 2002.

[3] R. Munir, Matematika Diskrit, Bandung: Informatika, 2007.

[4] P. Siagian, Penelitian Operasional: Teori dan Praktek, Jakarta: Universitas Indonesias Press, 1987. 